\title{
Impacts of Preeclampsia on the Brain of the Offspring
}

\section{Impactos da pré-eclâmpsia no cérebro de nascituros}

\author{
Frances Dang ${ }^{1} \quad$ B. Anne Croy ${ }^{1}$ Patrick W. Stroman ${ }^{2}$ \\ ${ }^{1}$ Department of Biomedical and Molecular Sciences, Queen's \\ University, Kingston, ON, Canada \\ ${ }^{2}$ Centre for Neuroscience Studies, Queen's University, Kingston, ON, Canada \\ ${ }^{3}$ School of Medicine, Universidade Federal do Mato Grosso do Sul, \\ FAMED-UFMS, Campo Grande, MS, Brazil
}

\begin{abstract}
Address for correspondence Ernesto Antonio Figueiró-Filho, MD, Ob\&Gyn, Maternal Fetal Medicine, PhD, School of Medicine, Universidade Federal do Mato Grosso do Sul, (FAMED-UFMS), Campo Grande, MS, Brazil (e-mail: eaff@queensu.ca).
\end{abstract}

Rev Bras Ginecol Obstet 2016;38:416-422.

\section{Abstract \\ Keywords \\ - preeclampsia \\ - PGF \\ - fetal brain \\ - MRI \\ - cognitive development}

\section{Resumo}

Preeclampsia (PE) is a significant gestational disorder that causes complications in 3$5 \%$ of all human pregnancies. Apart from the immediate risks and complications for mother and fetus, both additionally carry elevated lifelong risks for specific complications. Offspring of PE pregnancies (PE-F1) have higher risks for hypertension, stroke and cognitive impairment compared with well-matched offspring (F1) from uncomplicated pregnancies. Prior to the clinical onset of PE, placental angiokines secreted into the maternal plasma are deviated. In many PE patients this includes deficits in placental growth factor (PGF). Our laboratory found that mice genetically-deleted for PGF (PGF - I - ) have altered cerebrovascular and brain neurological development detectable from midgestation to adulthood. We hypothesized that the PGF deficits seen in human PE, deviate fetal cerebrovascular and neurological development in a manner that impairs cognitive functions and elevates stroke risk. Here we summarize the initial analytical outcomes from a pilot study of 8-10 year old male and female PE-F1s and matched controls. Our studies were the first to report magnetic resonance imaging (MRI), magnetic resonance angiography (MRA) and functional brain region assessment by eye movement control and clinical psychometric testing in PE-F1s. Further studies in larger cohorts are essential to define whether there are image-based biomarkers that describe unique anatomical features in PE-F1 brains.

A pré-eclampsia (PE) é importante doença gravídica complicando 3-5\% de todas as gestações humanas. Além dos riscos imediatos e complicações para a mãe e o feto, a PE associa-se a outros riscos materno-fetais elevados em longo prazo. Nascituros de gestações complicadas por PE (PE-F1) apresentam maiores riscos de desenvolver hipertensão, acidente vascular cerebral e disfunção cognitiva em comparação com prole (F1) de gestações sem complicações. Antes do aparecimento clínico da PE, angiocitocinas placentárias secretadas no plasma materno apresentam-se alteradas. Em muitos pacientes com $\mathrm{PE}$, isso inclui valores plasmáticos reduzidos de Fator de Crescimento Placentário (PGF). Nosso laboratório identificou que camundongos received

March 24, 2016

accepted

April 25, 2016

published online

July 15,2016
DOI http://dx.doi.org/

$10.1055 / \mathrm{s}-0036-1584515$. ISSN 0100-7203.
Copyright $(2016$ by Thieme Publicações License terms Ltda, Rio de Janeiro, Brazil
(ब) (1) $\circledast$ 


\author{
Palavras-chave \\ - pré-eclâmpsia \\ - PGF \\ - cérebro fetal \\ - RNM \\ - desenvolvimento \\ cognitivo
}

geneticamente não produtores de PGF (PGF - / - ) apresentam alterações vasculares e de desenvolvimento cerebral detectáveis do período gestacional à idade adulta. Nossa hipótese é que os déficits de PGF identificados em mulheres que desenvolveram PE podem desviar o desenvolvimento neurológico e vascular cerebral fetal, de maneira a prejudicar funções cognitivas, elevando o risco de AVC. Aqui resumimos os resultados analíticos iniciais de um estudo piloto com crianças do sexo masculino e feminino de 810 anos de idade nascidas de mães que tiveram PE (PE-F1s) comparadas com crianças controle pareadas por idade e sexo. Nossos estudos são os primeiros a relatar a ressonância magnética (RNM), a angiorressonância e a avaliação funcional do cérebro pelo controle de movimento dos olhos e pelo teste clínico psicotécnico em PE-F1s. Estudos adicionais em coortes maiores são essenciais para definir se há biomarcadores com base em imagens que possam descrever características anatômicas únicas em cérebros de crianças PE-F1.

\section{Introduction}

Preeclampsia (PE) is a significant clinical gestational disorder occurring in $3-5 \%$ of all human pregnancies, and is among the leading causes of maternal and fetal morbidity and mortality. ${ }^{1}$ PE accounts for up to $12 \%$ of all annual global maternal deaths, ${ }^{2}$ and up to $25 \%$ of all annual global fetal and neonatal deaths. ${ }^{3} \mathrm{PE}$ by definition is new-onset hypertension ( $>140 / 90 \mathrm{mmHg}$ ) and at least one of: proteinuria ( $>300 \mathrm{mg} /$ day), thrombocytopenia $\left(<10^{5} / \mathrm{uL}\right)$, renal insufficiency (serum creatinine $>1.1 \mathrm{mg} / \mathrm{dL}$ ), impaired liver function, pulmonary edema, headaches or visual disturbances after the 20th week of gestation. ${ }^{4}$ The systemic presentation of PE has been best explained as systemic vascular inflammation. ${ }^{5}$ Numerous disturbances in the levels of angiogenic molecules precede and accompany clinical signs, such as low placental growth factor (PGF) and elevation of the soluble form of its receptor (sFLT1). ${ }^{6,7}$

Beyond the immediate gestational complications of PE, numerous long-term maternal complications have been identified. $^{8-10}$ Women who have experienced PE have significantly increased risks of developing future cardiovascular risk factors such as dyslipidemia, ${ }^{11}$ hypertension ${ }^{12}$ and metabolic disease. ${ }^{13} \mathrm{PE}$ at least doubles the risk of future heart disease, ${ }^{14,15}$ elevating lifetime risks for coronary artery disease, ${ }^{16}$ cardiovascular disease and stroke. ${ }^{17}$

This review explores the impact of preeclampsia upon the brain of offspring from preeclamptic gestations. While PE's impact on brain vascular and neurological development occurs during fetal life, postnatal brain assessments are used to study the legacy of the preeclamptic gestation in the offspring. Preliminary outcomes of a novel pilot investigation that we undertook in 8-10-year-old children born from singleton PE gestations (PE-F1) are also discussed. ${ }^{18}$ These studies were the first to report Magnetic Resonance Imaging (MRI), Magnetic Resonance Angiography (MRA) and functional brain region assessment using eye movement control testing in PE-F1s. ${ }^{19}$ A mechanistic pathway for PE-induced deviations in brain development is proposed from a mouse model of PGF deficiency. Finally, some ideas regarding screening and future approaches for potential therapeutic interventions are introduced, should further studies of larger populations support the pilot study findings.

\section{Methods}

The MEDLINE database to March 2016 was searched for articles published in English between 1990-2016 that focused on preeclampsia but additionally mentioned brain function or cognition of offspring. The search terms used were: preeclampsia, cognition, cognitive tests, fetal, brain, offspring, children, newborn, and eye movements (or any of its synonyms). This database screen identified 277 publications. After reading the title and/or abstract, many of these publications were judged to be relevant and were not included in this review. A total of 57 articles were relevant and provided the basis for this review.

\section{Preeclampsia (PE) and Effects on PE-F1s}

Offspring born to PE pregnancies (PE-F1s) exhibit elevated lifetime risks for several health disorders and impaired functional capacities across multiple body systems, including the cardiovascular, endocrine and neurological systems. ${ }^{20-22}$ In particular, PE-F1s from the Helsinki Birth Cohort ${ }^{23}$ are reported to have deficits in cognitive function and elevated stroke risk. ${ }^{24-26}$

During childhood and young adulthood, PE-F1s display a body mass index (BMI) $0.6 \mathrm{~kg} / \mathrm{m}^{2}$ higher than children born to uncomplicated pregnancies. ${ }^{27}$ These PE-F1s also display $2.5 \mathrm{mmHg}$ higher systolic and $1.4 \mathrm{mmHg}$ higher diastolic blood pressure during the same timeframe. ${ }^{27}$ These increases in pressure translate to an approximate 2-fold increased risk of stroke in adulthood. ${ }^{26}$

PE-F1s are also more likely to experience cerebrovascular and cognitive related disorders than offspring born to non-PE pregnancies matched for gestation length and current age or maternal hypertension during the index pregnancy. ${ }^{28}$ As children, PE-F1s exhibit deficits in several cognitive function domains, ${ }^{28}$ including verbal reasoning. ${ }^{29}$ They also score lower for total intelligence quotient (IQ) ${ }^{30}$ and mental development indices (MDI). ${ }^{31,32}$ As these children move through adolescence and adulthood, deficits in verbal and arithmetic reasoning persist. $^{28}$ During adulthood and up to old age, PE-F1s display more depressive symptoms and higher rates of cognitive decline. $^{24}$ - Table 1 summarizes key findings related to the PE-F1 brain and cognition that have been published to date. 
Table 1 Brain and cognition related main findings previously reported in humans.PE-F1s

\begin{tabular}{|l|l|}
\hline Author (year) & Findings in PE-F1s \\
\hline Many et $\mathrm{al}^{30}(2003)$ & Lower IQ scores \\
\hline Kajantie et $\mathrm{al}^{26}(2009)$ & Smaller head circumferences at birth; elevated risk of stroke \\
\hline Tuovinen et $\mathrm{al}^{24}(2010)$ & Higher rates of depression \\
\hline Whitehouse et $\mathrm{al}^{29}(2012)$ & Reduced verbal ability \\
\hline Tuovinen et $\mathrm{al}^{23}(2012)$ & Greater cognitive decline at old ages \\
\hline Morsing and Maršál ${ }^{32}(2014)$ & Lower mean verbal IQ (VIQ) and lower full scale IQ (FSIQ) \\
\hline Rätsep et al ${ }^{18}(2015)$ & $\begin{array}{l}\text { Enlarged brain regional volumes in five regions (cerebellum, temporal lobe, } \\
\text { brainstem and right and left amygdala) }\end{array}$ \\
\hline Rätsep et $\mathrm{al}^{19}(2016)$ & Deficits in working memory and visuospatial processing \\
\hline
\end{tabular}

Abbreviations: PE- F1, offspring of preeclampsia pregnancies; IQ, intelligence quotient; VIQ, verbal intelligence quotient; FSIQ, lower full scale intelligence quotient.

\section{Preeclampsia (PE) and Placenta Growth Factor (PGF) - A Close Relationship}

During human pregnancy, several angiogenic factors become expressed at increased levels to support the growth, development and viability of the conceptus through an uncomplicated pregnancy. ${ }^{33}$ In particular, vascular endothelial growth factor (VEGF) and its related family member, placental growth factor (PGF), are highly expressed at predictable times over pregnancy. ${ }^{33}$ A deficiency in maternal plasma PGF has been linked to an increased likelihood of PE. ${ }^{6}$ The primary source for the gestational elevation of angiokines is the placenta. ${ }^{34}$

PGF serves as a biomarker predictive of PE, particularly when combined with clinical factors such as blood pressure ${ }^{35-37}$ or other angiogenic markers such as soluble fms-like tyrosine kinase- 1 (sFLT) ${ }^{38}$ and soluble endoglin (sENG). ${ }^{6,35,39}$ In addition, low maternal levels of PGF in early to mid-pregnancy are thought to be a marker for distinguishing between two types of PE. ${ }^{36}$

Mouse studies suggest that the normal gestational roles of PGF are to optimize vascular development within decidua basalis and to sustain normal maternal cardiac function in late gestation. ${ }^{40,41}$ In mice genetically engineered to be PGFdeficient (PGF $-1-$ ), our laboratory identified reduced and aberrant vascular branching in the decidua basalis during early pregnancy (gestation days (GD) 6.5-9.5 of the term 19 day mouse gestation $)^{40}$ and enlarged labyrinthine vascular spaces in late placentas (GD 15.5-18.5). The latter finding was interpreted as a negative feature resulting from reduced vascular branching into capillaries in the placental exchange region. ${ }^{40}$

Pilot Study Brain and Cognitive Outcomes for PE-F1s A recent pilot study ${ }^{18}$ used 8-10 year old children $(n=20)$ whose mothers were part of a research cohort, the Preeclampsia Network (PE-NET). ${ }^{13}$ Five boys and five girls whose mothers' pregnancies were complicated by $\mathrm{PE}$ ( $n=10)$ were matched by sex, gestation and current age with children who experienced normal pregnancies $(n=10)$. All pregnancies were singleton. All of the children were assessed by the same protocol, which included clinical cognitive testing (NEPSY II), eye movement control tests and Magnetic Resonance Imaging and Angiography (MRI/MRA) data collection sequences. ${ }^{18}$ The consented and assented children underwent MRI/MRA to evaluate their brain structural and vascular anatomy. The PE-F1s exhibited enlarged brain regional volumes in five regions (cerebellum, temporal lobe, brainstem and right and left amygdalae) when compared with their cohort-matched controls. ${ }^{18}$ Diffusion Tension Image (DTI) analysis suggests further alterations (manuscript in preparation).

Time of flight (TOF) MRA analysis data revealed significant differences in the occipital and parietal lobes. In both the occipital and parietal lobes, the mean vessel radius was significantly shorter in the PE group (control: $0.50 \pm 0.01 \mathrm{~mm}$ versus PE: $0.45 \pm 0.01 \mathrm{~mm}, p=0.004$; control: $0.55 \pm 0.01 \mathrm{~mm}$ versus PE $0.52 \pm 0.01 \mathrm{~mm}, p=0.025$ respectively). ${ }^{18}$ To understand the significance of the MRA findings, an MRI sequence for Arterial Spin Labeling (ASL) could be conducted, and would determine if brain perfusion is lower in regions with smaller caliber blood vessels.

Psychometric testing outcomes revealed overall deficits in working memory and visuospatial processing amongst PEF1s. ${ }^{19}$ These deficits appear to correlate with the anatomic alterations identified in our MRI analysis within the occipital lobe, parietal lobe, cerebellum and brain stem. Eye movement control impairments also correlate with several of the regions that showed structural deviation in PE-F1s. ${ }^{19}$

Plasma samples collected at term from the mothers of 12 study participants were available for PGF quantification by enzyme linked immunosorbent assay. Samples from the PE mothers had significantly lower levels of PGF than samples from the control mothers (control: $221.0 \pm 46.6 \mathrm{pg} / \mathrm{mL}$ versus PE: $37.2 \pm 21.5 \mathrm{pg} / \mathrm{mL}, p=0.024)$. This suggests that at least some of the PE-F1 study participants had aberrant placental PGF production. The PGF overall data were non-correlative and do not indicate that fetal PGF levels were lower than normal. The data also do not exclude the possibilities that other angiogenic or neurodevelopmental pathways provide a primary etiology to explain the findings of this pilot study. Power calculations based on these data 
estimate 76 pairs of PE-F1 and control children would be needed within a single time window of PE (that is, term or late preterm) to validate the observed anatomic differences.

\section{Preeclampsia-deviated Brain Development - A Proposed Pathway}

Fetal brain undergoes great constitutional change and growth during development to build the structural, vascular and neurological anatomy that supports future autonomic and cognitive functions. Because the brain requires oxygen and nutrients provided by circulation, development of the fetal cerebral circulation is coincident with brain neural development, and both tissues share many common molecular pathways. ${ }^{42}$ Axon induction, guidance and arterial specification all use VEGF and PGF. ${ }^{43}$

Fetal human brain development begins with the formation of the neural tube at gestational age (GA)3-4 weeks. ${ }^{44}$ Following neural tube closure, the rostral portion differentiates into three vesicles that eventually form the forebrain, midbrain and hindbrain. ${ }^{44}$ Simultaneously, the fetal cerebral vasculature forms. Six pairs of brachial arches, each containing primitive branchial arch arteries, are present at approximately GA18 days. ${ }^{45}$ The internal carotid arteries, which supply the anterior portion of the developing fetal brain, begin to form at GA24 days. At GA28 days, each internal carotid artery splits into anterior and posterior divisions, driven by the formation of the brain stem and the occipital lobe. ${ }^{45,46}$ Once the main branches of the cerebral arterial tree have formed, the fetal brain utilizes this blood supply to grow rapidly. Neurons begin to migrate along glial cell scaffolds, and the brain folds into gyri and sulci. ${ }^{47}$ In circumstances of maternal stress and uteroplacental nutrient deprivation, human fetal brain development takes priority over other tissues, with evidence of head sparing effects. ${ }^{48}$

PGF-deficient mice (PGF - / - ) display altered fetal brain vascular development by mid pregnancy (gestation day 10.5). ${ }^{40}$ The earliest deviations are in vessels of the hindbrain, then during development of the Circle of Willis (CW) and, in the early postpartum interval, the growing vascular plexus of the retina. ${ }^{49,50}$ These vascular alterations include narrower lumens, deficient collateral branching and atypical crossovers, deviations that persist into adulthood. Neuronal tissue structure is unlikely to be normal in these mice because adult differences in regional brain volumes have been detected by MRI, and behavior of the mice is atypical. Vascular alterations may underlie these neurological tissue changes, or they may be due to absence of PGF in the neurons themselves. ${ }^{50}$ PGF has been studied as a member in the cytokine network of Wallerian Degeneration. ${ }^{51}$ After injury, PGF - $1-$ mice have decreased Schwann cell proliferation and present less macrophage invasion than matched inbred controls, resulting in poorer functional recovery. ${ }^{51}$

Overall, these mouse studies suggest PGF plays a crucial role in neurovascular development, and that its deficiency contributes to long-term neuropathology. ${ }^{50}$ Since PGF appears to occur at all stages of brain development, ${ }^{50}$ it is unclear exactly when the phase of suboptimal human gestational PGF occurs, but reports have indicated it to be around the end of the first trimester. ${ }^{7}$ Overlapping of timeframes for suboptimal placen- tal PGF production and CW development occur in humans. ${ }^{50}$ The Circle of Willis is formed between the first and second months of pregnancy (40-55 days), ${ }^{52}$ and low PGF levels are present in maternal plasma in the majority of women who develop PE during the first trimester ${ }^{53}$ and as early as week 7.

If genetic and/or epigenetic mechanisms down-regulate PGF prior to embryonic gastrulation, the derivatives of both inner cell mass and trophectoderm cell lineages would be expected to have similar PGF deficient phenotypes. Therefore, vascular alterations in F1s are to be expected from PGFinsufficient PE pregnancies. To date, PGF levels across gestation have been followed in human placenta and maternal plasma but not the fetus. $^{38,54}$

We hypothesized that the mechanisms deviating placenta-derived angiokines in the circulations of women who progress to PE are established prior to blastocyst formation, and are as equally expressed in the tissue derivatives of the inner cell mass, that is, the fetus ${ }^{6,33,35,37,39}$ (-Fig. 1), as in the placenta. This hypothesis implicates deviations in fetal synthesis of PGF or other angiokines, rather than maternal hypertension or deviated placental angiokine synthesis as potential mechanisms that could compromise brain vascular development, brain structure and cognitive functions of PEF1s. This hypothesis additionally suggests that deviations in PE-F1 vascular development are widespread and not restricted to the brain. This may be a component of the elevated cardiovascular disease risk reported in PE-F1s.

\section{Significance}

The combination of MRI studies with neurocognitive tests is a proven approach to identify and link deviations in brain structure with cognition for several childhood conditions. ${ }^{55-57}$ Data from the detailed pilot studies that combined MRI/MRA, eye movement control and cognitive function tests of $8-10$ year old PE-F1s ${ }^{18,19}$ strongly suggest that extension of this approach to PE-F1s will identify consistent vascular and neuroanatomic anomalies, that is, an image phenotype of the PE-F1 brain. This phenotype may explain the cognitive deviations and elevated stroke risk that have been reported in pediatric or adult PE-F1 populations.

The neurocognitive subtests chosen for the pilot study were those used for children participating in NeuroDevNet's studies. NeuroDevNet is a Canadian Centers of Excellence Consortium (http://www.neurodevnet.ca/) that studies neurological brain development and function in children with Fetal Alcohol Spectrum Disorder, Cerebral Palsy and Autism Spectrum Disorder. Selection of these testing paradigms gives the additional exciting possibility for future research outcome comparisons between PE-F1s and children with other major neurodevelopmental disorders. ${ }^{56,57}$

Further work to define image-based biomarkers describing a unique PE-F1 brain anatomy could lead to personalized interventions and therapies aimed at preventing the development of fetal brain aberrations or their postnatal amelioration. For both the parents and the PE-F1 child, knowledge of the impacts of a PE gestational complication may lead to brainregion specific enhanced educational support to improve the 


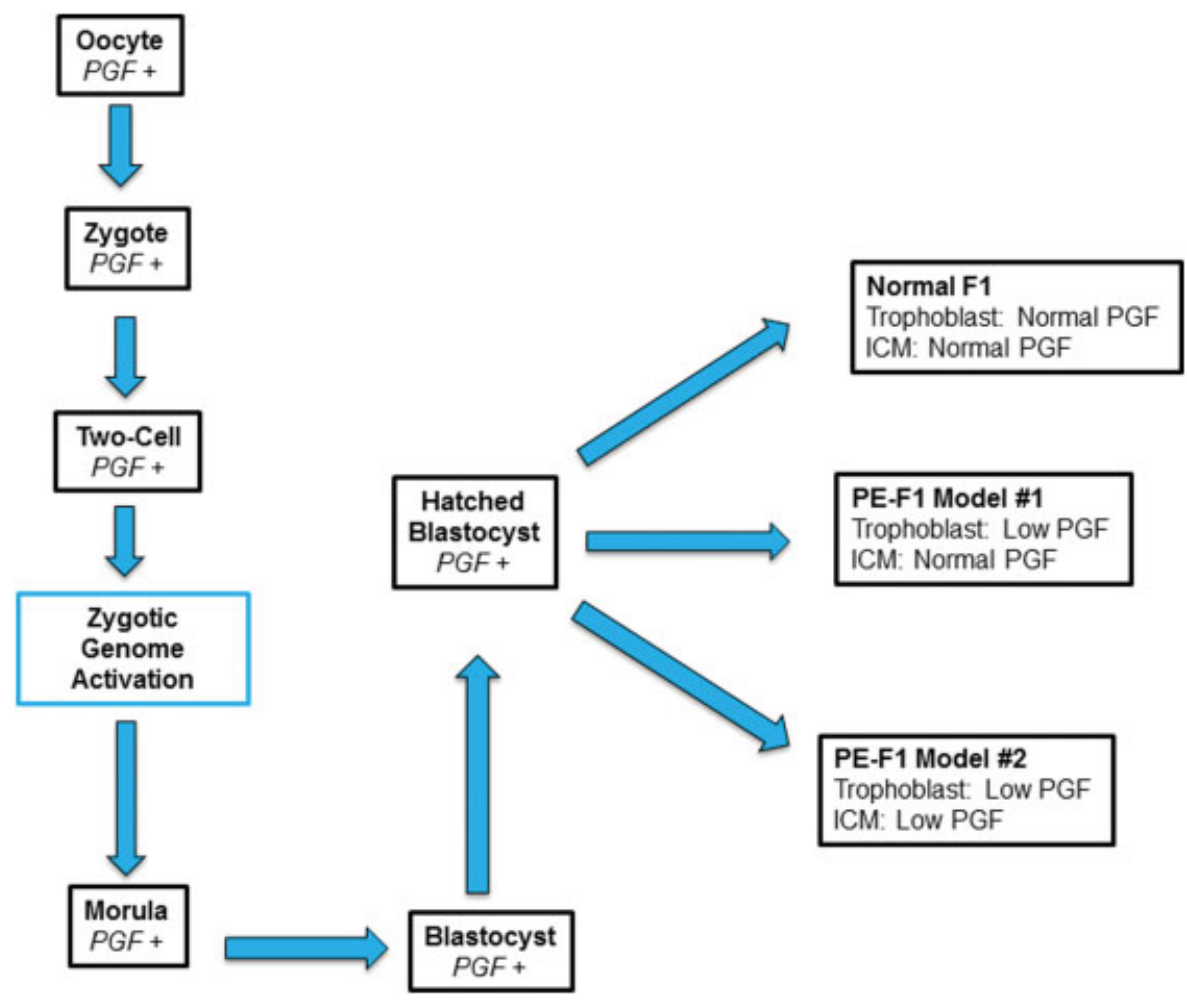

Fig. 1 PGF Expression During Human Preimplantation Development. PGF is expressed by the Oocyte, Zygote, Two-cell Embryo and, after Zygotic Genome Activation, by the Morula and Blastocyst. At the window of implantation, hatched Blastocysts will show one of three patterns for PGF expression. Normal F1: In Normal pregnancies - Normal Expression of PGF on ICM and in Trophoblast PE-F1 Model \#1 (Classic PE): Low PGF in Trophoblast and thus in maternal plasma over gestation but PGF levels are normal in ICM and its derivative tissues (includes membranes and embryo/fetus) PE-F1 Model \#2 (Our hypothesis): Low PGF in both Trophoblast and thus in maternal plasma over gestation, and PGF levels are low in ICM and its derivative tissues (includes membranes and embryo/ fetus) Abbreviations: PGF, placental growth factor; PE, preeclampsia; ICM, inner cell mass.

child's typical academic and social progress, and to the consideration of stroke prevention prophylaxis at younger ages. The relatively small sample size and racial homogeneity (Caucasian) of the pilot study participants are weaknesses.

\section{Conclusion}

Gestations that include fetal exposure to PE appear to elevate risk for altering cerebral vascular and neuroanatomy during development. Such changes during fetal life may explain the postnatal findings of elevated risks for stroke and specific deviations in cognitive functioning, including visual spatial processing and memory. A large, appropriately controlled, cohort study is needed to validate the current findings. Characterization of a PE-F1 "brain imaging signature" could eventually help identify individuals who may need enhanced educational or medical support.

\section{Acknowledgments}

We thank Drs. Nils Forkert (University of Calgary), James Reynolds, Graeme Smith, Matthew Rätsep, and Mr. Brandon Maser (Queen's University) for their helpful discussions and collaboration. We additionally thank all of the children and parents who participated in the study conducted at Queen's University. This study was supported by Awards from the Harry Botterell Foundation for the
Neurological Sciences Award and the Garfield Kelly Cardiovascular Research Development Fund from Kingston General Hospital Foundation, the Canada Research Chairs Program (PWS; BAC), and a Postdoctoral Training Award (Estágio Sênior, Grant 99999.002771/2015-02) from CAPES, Brazil (EAFF).

\section{References}

1 American College of Obstetricians and Gynecologists; Task Force on Hypertension in Pregnancy. Hypertension in pregnancy. Report of the American College of Obstetricians and Gynecologists' Task Force on Hypertension in Pregnancy. Obstet Gynecol 2013; 122(5):1122-1131

2 Duley L. The global impact of pre-eclampsia and eclampsia. Semin Perinatol 2009;33(3):130-137

3 Lo JO, Mission JF, Caughey AB. Hypertensive disease of pregnancy and maternal mortality. Curr Opin Obstet Gynecol 2013;25(2): 124-132

4 Tranquilli AL, Dekker G, Magee L, et al. The classification, diagnosis and management of the hypertensive disorders of pregnancy: A revised statement from the ISSHP. Pregnancy Hypertens 2014; 4(2):97-104

5 Ahmed A, Ramma W. Unravelling the theories of pre-eclampsia: are the protective pathways the new paradigm? $\mathrm{Br} J$ Pharmacol 2015;172(6):1574-1586

6 Torry DS, Wang HS, Wang TH, Caudle MR, Torry RJ. Preeclampsia is associated with reduced serum levels of placenta growth factor. Am J Obstet Gynecol 1998;179(6 Pt 1):1539-1544 
7 Levine RJ, Maynard SE, Qian C, et al. Circulating angiogenic factors and the risk of preeclampsia. N Engl J Med 2004;350(7):672-683

8 Lykke JA, Langhoff-Roos J, Sibai BM, Funai EF, Triche EW, Paidas MJ. Hypertensive pregnancy disorders and subsequent cardiovascular morbidity and type 2 diabetes mellitus in the mother. Hypertension 2009;53(6):944-951

9 Melchiorre K, Sutherland GR, Liberati M, Thilaganathan B. Preeclampsia is associated with persistent postpartum cardiovascular impairment. Hypertension 2011;58(4):709-715

10 Mongraw-Chaffin ML, Cirillo PM, Cohn BA. Preeclampsia and cardiovascular disease death: prospective evidence from the child health and development studies cohort. Hypertension 2010; 56(1):166-171

11 Magnussen EB, Vatten LJ, Myklestad K, Salvesen KÅ, Romundstad PR. Cardiovascular risk factors prior to conception and the length of pregnancy: population-based cohort study. Am J Obstet Gynecol 2011;204(6):526.e1-526.e8

12 Magnussen EB, Vatten LJ, Lund-Nilsen TI, Salvesen KA, Davey Smith G, Romundstad PR. Prepregnancy cardiovascular risk factors as predictors of pre-eclampsia: population based cohort study. BMJ 2007;335(7627):978

13 Smith GN, Walker MC, Liu A, et al; Pre-Eclampsia New Emerging Team (PE-NET). A history of preeclampsia identifies women who have underlying cardiovascular risk factors. Am J Obstet Gynecol 2009;200(1):58.e1-58.e8

14 Rich-Edwards JW, Fraser A, Lawlor DA, Catov JM. Pregnancy characteristics and women's future cardiovascular health: an underused opportunity to improve women's health? Epidemiol Rev 2014;36:57-70

15 Sattar N, Greer IA. Pregnancy complications and maternal cardiovascular risk: opportunities for intervention and screening? BMJ 2002;325(7356):157-160

16 Irgens HU, Reisaeter L, Irgens LM, Lie RT. Long term mortality of mothers and fathers after pre-eclampsia: population based cohort study. BMJ 2001;323(7323):1213-1217

17 Bushnell C, Chireau M. Preeclampsia and Stroke: Risks during and after Pregnancy. Stroke Res Treat 2011;2011:858134

18 Rätsep MT, Paolozza A, Hickman AF, et al. Brain structural and vascular anatomy is altered in offspring of pre-eclamptic pregnancies: a pilot study. AJNR Am J Neuroradiol 2015; [Epub ahead of print]

19 Rätsep MT, Hickman AF, Maser B, et al. Impact of preeclampsia on cognitive function in the offspring. Behav Brain Res 2016; 302:175-181

20 Lazdam M, de la Horra A, Pitcher A, et al. Elevated blood pressure in offspring born premature to hypertensive pregnancy: is endothelial dysfunction the underlying vascular mechanism? Hypertension 2010;56(1):159-165

21 Seidman DS, Laor A, Gale R, Stevenson DK, Mashiach S, Danon YL. Pre-eclampsia and offspring's blood pressure, cognitive ability and physical development at 17-years-of-age. Br J Obstet Gynaecol 1991;98(10):1009-1014

22 Tenhola S, Rahiala E, Martikainen A, Halonen P, Voutilainen R. Blood pressure, serum lipids, fasting insulin, and adrenal hormones in 12-year-old children born with maternal preeclampsia. J Clin Endocrinol Metab 2003;88(3):1217-1222

23 Tuovinen S, Räikkönen K, Pesonen AK, et al. Hypertensive disorders in pregnancy and risk of severe mental disorders in the offspring in adulthood: the Helsinki Birth Cohort Study. J Psychiatr Res 2012;46(3):303-310

24 Tuovinen S, Räikkönen K, Kajantie E, et al. Depressive symptoms in adulthood and intrauterine exposure to pre-eclampsia: the Helsinki Birth Cohort Study. BJOG 2010;117(10):1236-1242

25 Tuovinen S, Eriksson JG, Kajantie E, et al. Maternal hypertensive disorders in pregnancy and self-reported cognitive impairment of the offspring 70 years later: the Helsinki Birth Cohort Study. Am J Obstet Gynecol 2013;208(3):200.e1-200.e9
26 Kajantie E, Eriksson JG, Osmond C, Thornburg K, Barker DJ. Preeclampsia is associated with increased risk of stroke in the adult offspring: the Helsinki birth cohort study. Stroke 2009;40(4): $1176-1180$

27 Davis EF, Lazdam M, Lewandowski AJ, et al. Cardiovascular risk factors in children and young adults born to preeclamptic pregnancies: a systematic review. Pediatrics 2012;129(6): e1552-e1561

28 Tuovinen S, Eriksson JG, Kajantie E, Räikkönen K. Maternal hypertensive pregnancy disorders and cognitive functioning of the offspring: a systematic review. J Am Soc Hypertens 2014;8(11):832-47.e1

29 Whitehouse AJ, Robinson M, Newnham JP, Pennell CE. Do hypertensive diseases of pregnancy disrupt neurocognitive development in offspring? Paediatr Perinat Epidemiol 2012;26(2): 101-108

30 Many A, Fattal A, Leitner Y, Kupferminc MJ, Harel S, Jaffa A. Neurodevelopmental and cognitive assessment of children born growth restricted to mothers with and without preeclampsia. Hypertens Pregnancy 2003;22(1):25-29

31 Spinillo A, Iasci A, Capuzzo E, Egbe TO, Colonna L, Fazzi E. Two-year infant neurodevelopmental outcome after expectant management and indicated preterm delivery in hypertensive pregnancies. Acta Obstet Gynecol Scand 1994;73(8):625-629

32 Morsing E, Maršál K. Pre-eclampsia- an additional risk factor for cognitive impairment at school age after intrauterine growth restriction and very preterm birth. Early Hum Dev 2014;90(2): 99-101

33 Carmeliet P, Ferreira V, Breier G, et al. Abnormal blood vessel development and lethality in embryos lacking a single VEGF allele. Nature 1996;380(6573):435-439

34 Charnock-Jones DS. Soluble flt-1 and the angiopoietins in the development and regulation of placental vasculature. J Anat 2002; 200(6):607-615

35 Lambert-Messerlian G, Eklund EE, Chien EK, et al. Use of first or second trimester serum markers, or both, to predict preeclampsia. Pregnancy Hypertens 2014;4(4):271-278

36 Powers RW, Roberts JM, Plymire DA, et al. Low placental growth factor across pregnancy identifies a subset of women with preterm preeclampsia: type 1 versus type 2 preeclampsia? Hypertension 2012;60(1):239-246

37 Staff AC, Benton SJ, von Dadelszen P, et al. Redefining preeclampsia using placenta-derived biomarkers. Hypertension 2013;61(5): 932-942

38 Zeisler H, Llurba E, Chantraine F, et al. Predictive value of the sFlt1:PIGF ratio in women with suspected preeclampsia. N Engl J Med 2016;374(1):13-22

39 Brennan LJ, Morton JS, Davidge ST. Vascular dysfunction in preeclampsia. Microcirculation 2014;21(1):4-14

40 Rätsep MT, Carmeliet P, Adams MA, Croy BA. Impact of placental growth factor deficiency on early mouse implant site angiogenesis. Placenta 2014;35(9):772-775

41 Aasa KL, Zavan B, Luna RL, et al. Placental growth factor influences maternal cardiovascular adaptation to pregnancy in mice. Biol Reprod 2015;92(2):44

42 Rätsep MT, Hickman AF, Croy BA. The Elsevier trophoblast research award lecture: Impacts of placental growth factor and preeclampsia on brain development, behaviour, and cognition. Placenta 2016; [Epub ahead of print]

43 Quaegebeur A, Lange C, Carmeliet P. The neurovascular link in health and disease: molecular mechanisms and therapeutic implications. Neuron 2011;71(3):406-424

44 Tau GZ, Peterson BS. Normal development of brain circuits. Neuropsychopharmacology 2010;35(1):147-168

45 Menshawi K, Mohr JP, Gutierrez J. A functional perspective on the embryology and anatomy of the cerebral blood supply. J Stroke 2015;17(2):144-158 
46 Kathuria S, Gregg L, Chen J, Gandhi D. Normal cerebral arterial development and variations. Semin Ultrasound CT MR 2011; 32(3):242-251

47 Lenroot RK, Giedd JN. Brain development in children and adolescents: insights from anatomical magnetic resonance imaging. Neurosci Biobehav Rev 2006;30(6):718-729

48 Baker J, Workman M, Bedrick E, Frey MA, Hurtado M, Pearson O. Brains versus brawn: an empirical test of Barker's brain sparing model. Am J Hum Biol 2010;22(2):206-215

49 Rätsep MT, Felker AM, Kay VR, Tolusso L, Hofmann AP, Croy BA. Uterine natural killer cells: supervisors of vasculature construction in early decidua basalis. Reproduction 2015;149(2):R91-R102

50 Luna RL, Kay VR, Rätsep MT, et al. Placental growth factor deficiency is associated with impaired cerebral vascular development in mice. Mol Hum Reprod 2016;22(2):130-142

51 Chaballe L, Close P, Sempels M, et al. Involvement of placental growth factor in Wallerian degeneration. Glia 2011;59(3):379-396

52 Van Overbeeke JJ, Hillen B, Tulleken CA. A comparative study of the circle of Willis in fetal and adult life. The configuration of the posterior bifurcation of the posterior communicating artery. J Anat 1991;176:45-54
53 Romero R, Nien JK, Espinoza J, et al. A longitudinal study of angiogenic (placental growth factor) and anti-angiogenic (soluble endoglin and soluble vascular endothelial growth factor receptor1) factors in normal pregnancy and patients destined to develop preeclampsia and deliver a small for gestational age neonate. J Matern Fetal Neonatal Med 2008;21(1):9-23

54 Cetin I, Mazzocco MI, Giardini V, et al. PIGF in a clinical setting of pregnancies at risk of preeclampsia and/or intrauterine growth restriction. J Matern Fetal Neonatal Med 2016;19:1-6[Epub ahead of print]

55 Paolozza A, Treit S, Beaulieu C, Reynolds JN. Response inhibition deficits in children with Fetal Alcohol Spectrum Disorder: relationship between diffusion tensor imaging of the corpus callosum and eye movement control. Neuroimage Clin 2014; 5:53-61

56 Paolozza A, Munn R, Munoz DP, Reynolds JN. An in-depth analysis of saccade metrics in children with fetal alcohol spectrum disorder (FASD). Int J Dev Neurosci 2015;47(A):57-58

57 Paolozza A, Munn R, Munoz DP, Reynolds JN. Eye movements reveal sexually dimorphic deficits in children with fetal alcohol spectrum disorder. Front Neurosci 2015;9:76 